УЛьяНОВ Дмитрий Владимирович - студент факультета социальных наук и массовых коммуникаций Финансового университета при Правительстве РФ (125993, Россия, г. Москва, ГСП-3, Ленинградский пр-кт, 49; d30091998@уа.ru)

\title{
«ЗЕЛЕНЫЕ» ПОЛИТИЧЕСКИЕ ПАРТИИ В СТРАНАХ ЕВРОПЕЙСКОГО СОЮЗА: ПРОЦЕССЫ ТРАНСФОРМАЦИИ
}

Аннотация. Данная статья посвящена анализу влияния «зеленых» политических партий в странах Европейского союза. Автор анализирует события, подтверждающие политические успехи «зеленых», вместе с ограничениями для «зеленого ренессанса». Особое внимание автор уделяет манифестам Европейской зеленой партии (ЕЗП) (“Социальное измерение Нового зеленого курса», 2012 и «Время обновить перспективу Европы», 2018), определяющим программные установки партии. Эпицентр распространения популярности «зеленых» Нидерланды, Австрия и Германия, где идет рост их рейтинга, что показали последние выборы - как национальные, так и локальные. «Зеленые» пользуются поддержкой молодежи, из-за чего имеют неплохие перспективы в будущем. Другая причина положительных перспектив «зеленых» - это трансформация с экологической партии на более широкую политическую силу.

Ключевые слова: «зеленые», Европейская зеленая партия, «Социальное измерение Нового зеленого курса», «Время обновить перспективу Европы», Европейский союз, постматериалистические ценности

$\mathrm{B}^{\mathrm{n}}$ представленной статье рассматривается влияние европейских «зеленых» на политические процессы в странах Европейского сюза. Актуальность данной темы обусловлена тем, что в настоящее время растет популярность этого движения. Исторически оно ориентировалось на сохранение природы, хотя с 2010-х его повестка развивается и в других сферах - социально-экономической, сфере безопасности, внешней политики. В 2012 г. Европейская зеленая партия в качестве программного документа приняла «Социальное измерение Нового зеленого курса», что свидетельствует об увеличении активности европейских «зеленых» за рамками экологической тематики.

Европейская зеленая партия (ЕЗП) была основана 22 февраля 2004 г. на IV Конгрессе Европейской федерации партий зеленых в Риме, в котором приняли участие более 1000 делегатов от 34 партий из всей Европы (в т.ч. и не из стран ЕС). По состоянию на март 2019 г. в ЕЗП входят 30 партий из 27 стран, в разной степени представленных в национальных парламентах (см. табл. 1).

Из табл. 1 следует, что самые стабильные позиции из всех стран ЕС «зеленые» занимают в Германии, Австрии и Финляндии (странах Северной и Западной Европы). До 2017-2019 гг. «зеленые» чаще всего оказывались вне исполнительной власти даже в западноевропейских странах (Франции, Испании, Германии), где их идеи пользовались популярностью. Пиком роста их позиций стала правительственная коалиция в Германии (с Социал-демократической партией Германии (СДПГ); 1998-2005). После ее распада началась маргинализация «зеленых», надолго выбывших из правительственных структур.

«Зеленый ренессанс» частично состоялся в условиях кризиса традиционной европейской социал-демократии, представители которой не смогли ответить на ряд внешних вызовов (например, на миграционный кризис в Европе). Члены Европейской зеленой партии после 2017 г. все активнее навязывают конкуренцию мейнстримным социалистам [Костюк 2019: 61]. В то же время влияние «зеленых» сильно ограничено (см. табл. 1). В посткоммунистических государствах Центральной и Восточной Европы идеи «зеленых» не прижи- 
Таблица 1

Партии стран ЕС, входящие в состав Европейской зеленой партии (ЕЗП)

\begin{tabular}{|c|c|c|c|}
\hline Партия - член ЕЗП & Страна & $\begin{array}{l}\text { Мест в Евро- } \\
\text { парламенте от } \\
\text { каждой страны }\end{array}$ & $\begin{array}{c}\text { Мест в национальном } \\
\text { парламенте }\end{array}$ \\
\hline $\begin{array}{l}\text { «Зеленые - Зеленая } \\
\text { Альтернатива» }\end{array}$ & Австрия & 3 из 19 & 26 из 183 \\
\hline «Зеленые» & $\begin{array}{l}\text { Бельгия (фла- } \\
\text { мандская } \\
\text { часть) }\end{array}$ & $\begin{array}{l}1 \text { из } 12 \text { (голландо- } \\
\text { язычная избира- } \\
\text { тельная коллегия) }\end{array}$ & $\begin{array}{l}6 \text { из } 102 \text { (фламандские } \\
\text { места в палате предста- } \\
\text { вителей Бельгии, В т.ч. } \\
\text { места для двуязычного } \\
\text { Брюсселя) }\end{array}$ \\
\hline «Эколо» & $\begin{array}{l}\text { Бельгия } \\
\text { (валлонская } \\
\text { часть и гер- } \\
\text { маноязычное } \\
\text { сообщество) }\end{array}$ & $\begin{array}{l}2 \text { из } 9 \text { (все места } \\
\text { для франко- и } \\
\text { немецкоязычных } \\
\text { избирательных } \\
\text { коллегий) }\end{array}$ & $\begin{array}{l}6 \text { из } 63 \text { (все места для } \\
\text { французских и немецко- } \\
\text { язычных сообществ в } \\
\text { палате представителей } \\
\text { Бельгии, включая места } \\
\text { для двуязычного Брюсселя) } \\
15 \text { из } 289 \text { (все места в пар- } \\
\text { ламентах Брюсселя, реги- } \\
\text { она Валлония, франко-- } \\
\text { язычной и немецкоязыч- } \\
\text { ной общин, а также места в } \\
\text { Брюсселе во фламандском } \\
\text { парламенте). }\end{array}$ \\
\hline $\begin{array}{l}\text { Зеленая партия } \\
\text { Болгарии }\end{array}$ & Болгария & - & - \\
\hline $\begin{array}{l}\text { Движение экологов - } \\
\text { Гражданское } \\
\text { сотрудничество }\end{array}$ & Кипр & - & 2 из 56 \\
\hline Партия зеленых & Чехия & - & - \\
\hline $\begin{array}{l}\text { Социалистическая } \\
\text { народная партия }\end{array}$ & Дания & 2 из 14 & 14 из 179 \\
\hline Эстонские зеленые & Эстония & - & - \\
\hline Зеленая лига & Финляндия & 3 из 14 & 20 из 200 \\
\hline $\begin{array}{l}\text { «Европа, экология, } \\
\text { зеленые» }\end{array}$ & Франция & 10 из 79 & $\begin{array}{l}0 \text { из } 577 \text { (во Франции } \\
\text { работает одномандатная } \\
\text { система с двумя турами) }\end{array}$ \\
\hline «Альянс 90/Зеленые» & Германия & 21 из 96 & 67 из 709 \\
\hline $\begin{array}{l}\text { Экологические } \\
\text { зеленые }\end{array}$ & Греция & - & - \\
\hline $\begin{array}{l}\text { Политика может быть } \\
\text { разной }\end{array}$ & Венгрия & 0 из 21 & 8 из 199 \\
\hline $\begin{array}{l}\text { Зеленая партия } \\
\text { Ирландии }\end{array}$ & Ирландия & 2 из 13 & 12 из 160 \\
\hline Федерация зеленых & Италия & - & - \\
\hline $\begin{array}{l}\text { Латвийская зеленая } \\
\text { партия }\end{array}$ & Латвия & - & 6 из 100 \\
\hline $\begin{array}{l}\text { Литовская зеленая } \\
\text { партия }\end{array}$ & Литва & - & 1 из 141 \\
\hline «Зеленые» & Люксембург & 1 из 6 & 6 из 60 \\
\hline
\end{tabular}




\begin{tabular}{|c|c|c|c|}
\hline $\begin{array}{l}\text { «Демократическая } \\
\text { альтернатива» }\end{array}$ & Мальта & - & - \\
\hline «Зеленые левые» & Нидерланды & 3 из 29 & 14 из 150 \\
\hline «Зеленые» & Польша & - & 3 из 460 \\
\hline «Свобода» & Португалия & - & 1 из 230 \\
\hline $\begin{array}{l}\text { «Люди-животные- } \\
\text { природа» }\end{array}$ & Португалия & 1 из 21 & 4 из 230 \\
\hline $\begin{array}{l}\text { Экологическая партия } \\
\text { «Зеленые» }\end{array}$ & Португалия & - & 2 из 230 \\
\hline Зеленая партия & Румыния & - & - \\
\hline Зеленая партия & Словакия & - & - \\
\hline $\begin{array}{l}\text { Молодежная партия - } \\
\text { европейские зеленые }\end{array}$ & Словения & - & - \\
\hline Экуо & Испания & 0 из 54 & 1 из 350 \\
\hline $\begin{array}{l}\text { Инициатива каталон- } \\
\text { ских зеленых }\end{array}$ & $\begin{array}{l}\text { Испания } \\
\text { (Каталония) }\end{array}$ & 1 из 54 & $\begin{array}{l}2 \text { из } 350 \text { (весь конгресс } \\
\text { депутатов; в отличие от } \\
\text { Бельгии, выделения регио- } \\
\text { нов в парламенте нет) }\end{array}$ \\
\hline Зеленая партия & Швеция & 3 из 21 & 16 из 344 \\
\hline
\end{tabular}

лись. Но и в западноевропейских государствах «зеленые» популярны далеко не везде: на юге региона (в Испании, Италии, Португалии) они занимают маргинальное положение. Маргиналами являются и французские «зеленые». Даже в Швеции, где популярны идеи экологизма (что подтвердила в т.ч. и деятельность Греты Тунберг), на выборах в риксдаг в 2018 г. «зеленые» с огромным трудом преодолели проходной барьер в $4 \%$.

Самые крепкие позиции у «зеленых» - в Германии и Австрии, а также странах Бенилюкса. Результаты различных выборов (как национальных, так и региональных и местных) и политическая повестка в Австрии и Германии показывают рост электоральных настроений в их поддержку. Влияние «зеленых» здесь выросло, в т.ч. благодаря вхождению в правительственные коалиции. Новым шагом в укреплении их положения стала коалиция консервативной Австрийской народной партии (АНП) с австрийскими «зелеными» (основаны в 1986 г.) в начале 2020 г. Последние лишь в 2013-2017 гг. не были представлены в парламенте, в остальное время своего существования имели в нем достаточно стабильные позиции. 2019 г. стал для них успешным, в первую очередь из-за коалиции с АНП (26 мест из 183). В Германии «зеленые» пока не вошли в состав правительства, но в начале 2020 г. их рейтинг составлял более $20 \%$ (больше только у ХДС/ХСС $-26-27 \%)^{1}$. А в западногерманских землях они сравнялись по рейтингу с ХДС/ХСС в конце 2019 г. Таким образом, «зеленые» в германском левом движении значительно обходят Социал-демократическую партию Германии (СДПГ, рейтинг 12-14\%) и «Линке» («Левые», 7-10\%). В табл. 2 указаны результаты «зеленых» и других левых партий (СДПГ и «Левые») на федеральных выборах 2013 и 2017 гг. Помимо результатов на федеральных выборах, в таблице указан рейтинг последних выборов и результат выборов в Европарламент от Германии.

1 Wenn am nächsten Sonntag Bundestagswahl wäre ... [Если бы в следующее воскресенье были выборы в бундестаг...]. - Wahlrecht. URL: http://www.wahlrecht.de/umfragen/forsa.htm (проверено 19.02.2020). 
Таблица 2

\begin{abstract}
Результаты «зеленых», СДПГ и «Левых» на федеральных выборах в Германии $(2013,2017)$ и выборах Германии в Европарламент, а также рейтинги после выборов, \%
\end{abstract}

\begin{tabular}{|l|c|c|c|}
\hline \multicolumn{1}{|c|}{ Дата } & $\begin{array}{c}\text { Результат (рейтинг) } \\
\text { «зеленых» }\end{array}$ & $\begin{array}{c}\text { Результат (рейтинг) } \\
\text { СДПГ }\end{array}$ & $\begin{array}{c}\text { Результат } \\
\text { (рейтинг) «Левых» }\end{array}$ \\
\hline 2013 (федеральные выборы) & 8,4 & 25,7 & 8,6 \\
\hline 2017 (федеральные выборы) & 8,9 & 20,5 & 9,2 \\
\hline 04.01 .20181 & 11 & 21 & 9 \\
\hline 14.06 .2018 & 13 & 18 & 10 \\
\hline 11.10 .2018 & 17 & 15 & 7 \\
\hline 10.01 .2019 & 20 & 15 & 5,5 \\
\hline 26.05 .2019 (выборы в & 20,5 & 11,5 & 8 \\
\hline Европарламент в Германии) & 27 & 12 & 9 \\
\hline 09.01 .2020 & 20 & 13 & 16 \\
\hline 05.03 .2020 & 23 & & \\
\hline
\end{tabular}

В таблице виден бурный рост популярности «зеленых», особенно во второй половине 2018 г. Падение популярности социал-демократов (в Германии их представляет СДПГ) объясняется разочарованием избирателей социал-демократов из-за отсутствия решения ключевых политических проблем (особенно миграционных и экологических) на фоне активности и новизны «зеленых». Аналогичные тенденции происходят и в Нидерландах, где гегемония социалдемократов в стане левых прекратилась на региональных/провинциальных выборах 2019 г. (см. табл. 3). В таблице выделены левоцентристские и/или левые партии.

Из табл. 3 видно, что рост числа мест «Зеленых левых» тесно связан с падением рейтинга Рабочей партии (дата основания 1946 г.) и особенно Социалистической партии (основана в 1971 г.) (обе - социал-демократические). В 2015 г. левое крыло нидерландского политического спектра отличалось преобладанием этих двух партий, тогда как «Зеленые левые» по популярности почти вдвое уступали Рабочей партии. В 2019 г. они нарастили свой рейтинг вдвое, обойдя Рабочую партию.

Одна из ключевых причин падения рейтинга традиционных социал-демократических партий - разочарование избирателей в их действиях. Во-первых, это отсутствие новизны в программах социал-демократов. Во-вторых, это сближение социал-демократов с правоцентристскими партиями, не устраивающее радикально настроенный электорат. Запрос многочисленных групп населения именно на повестку «зеленых» объясняется наибольшей последовательностью «зеленых» (а именно, ЕЗП) из всех участников левого движения в Европе. «Зеленые» - защитники углубления интеграционных процессов в ЕС вплоть до трансформации данного международного объединения в федерацию государств. Современное европейское строительство надгосударственного объединения с отдельными признаками государства (например, наличие общеевропейских властных органов) выглядит в их глазах противоречивым и недостаточным.

Политические позиции ЕЗП близки как к либерал-демократам из партии 
Таблица 3 Результаты нидерландских провинциальных выборов 2015 и 2019 гг.
Всего в парламентах провинций страны 570 мест 1

\begin{tabular}{|c|c|c|c|c|c|c|c|}
\hline 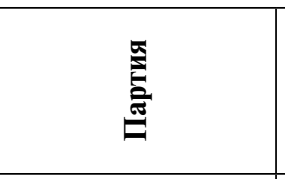 & 产 & 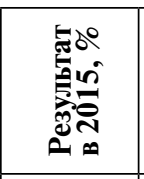 & 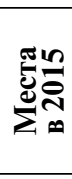 & 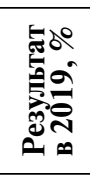 & 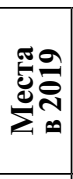 & 㺼 & 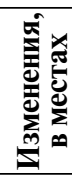 \\
\hline $\begin{array}{l}\text { Форум } \\
\text { за демократию }\end{array}$ & $\begin{array}{l}\text { Правый популизм, } \\
\text { евроскептиџизм, } \\
\text { голландский национализм }\end{array}$ & $\begin{array}{c}\text { не } \\
\text { участво- } \\
\text { вала } \\
\end{array}$ & - & 14,53 & 86 & $+14,53$ & +86 \\
\hline $\begin{array}{l}\text { Народная партия } \\
\text { за свободу } \\
\text { и демократию }\end{array}$ & $\begin{array}{l}\text { Либеральный } \\
\text { консерватизм, } \\
\text { евроинтеграция }\end{array}$ & 15,92 & 89 & 13,99 & 80 & $-1,93$ & -9 \\
\hline $\begin{array}{l}\text { Христианско-- } \\
\text { демократичес- } \\
\text { кий призыв } \\
\end{array}$ & Христианская демократия & 14,71 & 89 & 11,07 & 72 & $-3,64$ & -17 \\
\hline Зеленые левые & $\begin{array}{l}\text { Зеленая политика, } \\
\text { евроинтеграция }\end{array}$ & 5,35 & 30 & 10,76 & 61 & $+5,41$ & +31 \\
\hline Партия труда & Социал-демократия & 10,08 & 63 & 8,52 & 53 & $-1,56$ & -10 \\
\hline Демократы-66 & $\begin{array}{l}\text { Социал-либерализм, } \\
\text { щентризм, европейский } \\
\text { федерализм }\end{array}$ & 12,46 & 67 & 7,8 & 41 & $-4,66$ & -26 \\
\hline $\begin{array}{l}\text { Партия } \\
\text { за свободу }\end{array}$ & $\begin{array}{l}\text { Национал-либерализм, } \\
\text { правый популизм, } \\
\text { евроскептицизм, } \\
\text { антиисламская политика }\end{array}$ & 11,73 & 66 & 6,94 & 40 & $-4,79$ & -26 \\
\hline $\begin{array}{l}\text { Социалистичес- } \\
\text { кая партия }\end{array}$ & $\begin{array}{l}\text { Левый популизм, } \\
\text { демократический } \\
\text { социализм, социал- } \\
\text { демократия, мягкий } \\
\text { евроскептицизм }\end{array}$ & 11,65 & 70 & 5,91 & 35 & $-5,74$ & -35 \\
\hline $\begin{array}{l}\text { Христианский } \\
\text { союз }\end{array}$ & $\begin{array}{l}\text { Христианская } \\
\text { демократия, социальный } \\
\text { консерватизм, мягкий } \\
\text { евроскептицизм }\end{array}$ & 4,01 & 29 & 4,86 & 31 & $+0,85$ & +2 \\
\hline $\begin{array}{l}\text { Партия за } \\
\text { животных }\end{array}$ & $\begin{array}{l}\text { Права животных, защита } \\
\text { экологии, мягкий } \\
\text { евроскептицизм }\end{array}$ & 3,46 & 18 & 4,36 & 20 & $+0,9$ & +2 \\
\hline «50 Плюс» & $\begin{array}{l}\text { Центризм, защита } \\
\text { пенсионеров }\end{array}$ & 3,38 & 14 & 3,64 & 17 & $+0,26$ & +3 \\
\hline $\begin{array}{l}\text { Реформатская } \\
\text { партия }\end{array}$ & $\begin{array}{l}\text { Консерватизм, } \\
\text { клерикализм, } \\
\text { евроскептицизм }\end{array}$ & 2,81 & 18 & 2,47 & 14 & $-0,34$ & -4 \\
\hline ДЕНК & $\begin{array}{l}\text { Права меньшинств, } \\
\text { мультикультурализм, } \\
\text { социал-демократия }\end{array}$ & $\begin{array}{c}\text { не } \\
\text { участво- } \\
\text { вала } \\
\end{array}$ & - & 1,67 & 4 & $+1,67$ & +4 \\
\hline $\begin{array}{l}\text { Христианский } \\
\text { союз - Рефор- } \\
\text { матская партия } \\
\text { (список Северного } \\
\text { Брабанта) } \\
\end{array}$ & Консерватизм & 0,7 & 2 & 0,43 & 1 & $-0,27$ & -1 \\
\hline $\begin{array}{l}\text { Провинциальные } \\
\text { партии (они же } \\
\text { - Независимая } \\
\text { группа Сената; } \\
\text { места зарезерви- } \\
\text { рованы) } \\
\end{array}$ & - & - & 15 & - & - & 15 & 0 \\
\hline
\end{tabular}

1 Provinciale Staten 20 maart 2019. - Кіеsraad. Доступ: https://www.verkiezingsuitslagen.nl/ verkiezingen/detail/PS20190320/684842 (проверено 09.03.2020). 
«Обновим Европу», выступающим за «единую Европу», так и левым движениям, вплоть до самых радикальных, в социально-экономических вопросах. Ее евроинтеграционные позиции представлены в манифесте 2014 г., где они называют Европу «общим домом» [Change... 2014: 8].

При росте позиций правых популистов из партий «Идентичность и демократия» (ИД) и «Альянс европейских консерваторов и реформистов» (АЕКР) ЕЗП становится их оппонентом слева. Один из ключевых пунктов их расхождения - миграционный вопрос. Если правые популисты поддерживают ограничение иммиграции, особенно с Ближнего Востока и из Северной Африки, то «зеленые» поддерживают права и свободы внешних мигрантов и беженцев. Европа, согласно манифесту ЕЗП 2018-2019 гг., должна обеспечить легальные и безопасные каналы для миграции, лучшие рабочие места и возможности для вновь прибывших ${ }^{1}$.

Проевропейские силы после выборов в Европарламент в 2019 г. сохранили свои позиции, в т.ч. благодаря «зеленым», предложившим перспективную программу 2 . Согласно своему манифесту «Время обновить перспективу Европы» (2018 г.), они предлагают альтернативу нынешней европейской интеграции: социальную Европу с устойчивой экономикой и налоговой справедливостью. Каждый европеец будет иметь право на достойный доход и базовые общественные услуги, а «Новый зеленый курс» будет основан на инновациях и устойчивых исследованиях с соответствующими вложениями в них ${ }^{3}$. ЕЗП повлияла на политические процессы в Европе и использованием природоохранной тематики: эту практику стали чаще применять и другие европейские партии.

В ряде вопросов «зеленые» довольно радикальны. Даже на фоне левых партий они выделяются бо́льшим вниманием к защите юридических и социальных прав меньшинств: национальных (в т.ч. мигрантов и беженцев с Ближнего Востока и Северной Африки), религиозных (мусульман), сексуальных (представителей ЛГБТ-сообщества). ЕЗП видит развитие Европы в ее многообразии, о чем практически не говорят традиционные социал-демократы. Другое проявление радикализма «зеленых» - это неприятие репрессивной политики в отношении мигрантов и беженцев, исходящей от правых политических сил. Также радикализм европейских «зеленых» выражен в последовательности программы по внешней политике и общей безопасности, чего не хватает многим левым. В начале XXI в. «зеленые» поддерживали модификации общих европейских договоров (например, Лиссабонского), которые помогали совершенствовать общую дипломатию ЕС и его рычаги.

В долгосрочной перспективе у «зеленых» есть потенциал для развития, поддерживаемый четырьмя факторами. Один из них - более высокий уровень образования у их избирателей в сравнении с электоратом других партий [Власов 2019: 124]. Положительно влияет на перспективы «зеленых» рост популярности в Европе «постматериалистических» ценностей - экологии, равноправия и активности гражданского общества [Inglehart 1977: 5]. Третий фактор, укрепляющий позиции «зеленых», - симпатии молодежи [Власов 2019: 125]. Наконец, «зеленые» готовы сотрудничать с представителями практически всех политических сил, кроме правых популистов (АдГ, Австрийская партия свободы - АПС, нидерландский «Форум за демократию») и вступать в коалиции. Эту готовность подтверждает правительственная коалиция «зеленых» и

1 Time to Renew the Promise of Europe. Adopted EGP Manifesto 2019. Berlin. 2018. P. 12.

2 European Election Results. 2019. URL: https://www.europarl.europa.eu/election-results-2019/ en (accessed 30.05.2019).

3 Time to Renew the Promise of Europe. Adopted EGP Manifesto 2019. Berlin. 2018. P. 5. 
консерваторов из АНП, а также сотрудничество «зеленой» партии с ХДС/ХСС на земельном уровне в Германии, начиная с коалиции в Гамбурге, образовавшейся в 2008 г.

Несмотря на четыре указанных выше фактора, для «зеленых» в долгосрочной перспективе существует угроза в виде невозможности выполнить свою повестку в экологических вопросах. Им предстоит вступать в конфликты с промышленными лобби, сильными во многих европейских странах. Хотя, как показывает практика, попытки выхода Германии из угольной генерации 1 дают надежду избежать рисков провала программы «зеленых» на практике.

\title{
Список литературы
}

Власов Н.А. 2019. «Зеленые» в ФРГ: новая народная партия? -Современная Eвpona. № 2. С. 118-128.

Костюк Р.В. 2019. Левые альтернативы в кампании по выборам в Европейский парламент в 2019 году. - Современная Европа. № 5. С. 58-67.

Change Europe, Vote Green. 2014. Brussels: European Green Party. 39 p.

Inglehart R. 1977. The Silent Revolution: Changing Values and Political Styles among Western Public. Princeton, USA: Princeton University Press. XIII+481 p.

\section{GREEN POLITICAL PARTIES IN THE EUROPEAN UNION: TRANSFORMATION PROCESSES}

\begin{abstract}
This article analyzes the influence of green political parties in the European Union. The author analyzes the events that confirm the political success of the greens, along with the restrictions for the green Renaissance. The author pays special attention to the manifestos of the European Green party (ESP) - "The Social Dimension of the New Green Course» (2012) and "Time to Renew the Perspective of Europe» (2018), which define the party's program settings. The epicenter of spreading the popularity of the greens is in the Netherlands, Austria and Germany, where their rating is growing as the recent elections - both national and local-show. Greens enjoy the support of young people, that is why they have good prospects in the future. Another reason for the positive prospects of the greens is their transformation from an environmental party to a broader political force.
\end{abstract}

Keywords: greens, European Green party, "Social Dimension of the New Green Deal», "Time to Renew the Promise of Europe», European Union, post-materialist values

${ }^{1}$ Никифоров О. Германия выходит из угольной генерации. - Независимая газета. Доступ: http://www.ng.ru/ng_energiya/2019-02-11/15_7504_germany.html (проверено 26.08.2020). 